\title{
Lower eyelid fornix deepening: A new indication for the facial artery myomucosal flap
}

\author{
Arman Zaharil Mat Saad ${ }^{1,2}$, Nur Raihana Nordin ${ }^{1}$, Wan Azman Wan Sulaiman ${ }^{1}$, Nafij Jamayet ${ }^{3}$, \\ Siti Fatimah Noor Mat Johar ${ }^{1}$, Adil Hussein ${ }^{4}$ \\ ${ }^{1}$ Reconstructive Sciences Unit, School of Medical Sciences, Universiti Sains Malaysia, Kota Bharu; ${ }^{2}$ Plastic and Reconstructive Unit, MSU \\ Medical Centre, Management and Science University, Shah Alam; ${ }^{3}$ Department of Prosthodontics, School of Dental Sciences, Universiti Sains \\ Malaysia, Kubang Kerian; ${ }^{4}$ Department of Ophthalmology, School of Medical Sciences, Health Campus, Universiti Sains Malaysia, Kubang \\ Kerian, Malaysia
}

Eye socket contracture is a well-known late complication of enucleation surgery, and the additional insult of radiotherapy at an early age causes even further fibrosis and scarring of the socket. Management of the contracted socket is challenging, and several methods have been proposed. We report a case of eye socket contracture after enucleation and radiotherapy in which multiple reconstructive procedures failed. The recurrent contracture caused difficulty in housing and retaining the eye prosthesis. We reconstructed the lower eyelid with a facial artery myomucosal flap and nasolabial flap, and the upper eyelid with a Fricke flap following reconstruction of the orbital rims (supraorbital and infraorbital rims with a calvarial bone graft, and further augmentation of the infraorbital rim with a rib bone graft). Cosmesis postreconstruction was acceptable and the prosthesis was retained very well.

Keywords Orbit / Surgical flaps / Contracture / Eyelids

\section{Correspondence:}

Arman Zaharil Mat Saad

Plastic and Reconstructive Unit, MSU

Medical Centre, Management and

Science University, Off Persiaran

Olahraga, 40100 Shah Alam, Selangor,

Malaysia

Tel: $+60-355262600$

Fax: $+60-355262828$

E-mail:armanzaharil@gmail.com

Received: February 18, 2020 - Revised: June 2, 2020 • Accepted: June 18, 2020

pISSN: 2234-6163 • elSSN: 2234-6171 • https://doi.org/10.5999/aps.2020.00206 • Arch Plast Surg 2021;48:80-83

\section{INTRODUCTION}

Anophthalmic socket is defined by an orbit with no eyeball, but containing soft tissues and eyelid structures. The absence of the eyeball causes orbital volume deficiency, which leads to orbital soft tissue architectural changes [1]. The loss of the eye globe, if not replaced with adequate and appropriate volume, will lead to a multitude of complications. The surrounding soft tissue may atrophy and the socket may become contracted [2]. The contracture can be exacerbated by radiation therapy, which leads to the replacement of adipose tissue and extracellular matrix with dense fibrous tissue and atypical fibroblasts [3]. Autologous grafting (mucous membrane, skin, fat, dermis) is the preferred technique for the management of socket contracture $[4,5]$. In cases with concomitant lower lid malpositioning, an auricular graft can be used as a spacer to correct the problem [6]. Although autogenous grafts caused a minimal inflammatory reaction and better integration with the surrounding tissue, the unpredictable absorption rate of these grafts is a major drawback, leading to the requirement for repeated procedures, donor site morbidity, and a flat or concave appearance $[4,7]$. Here, we present our experience of reconstructing the eye socket in anophthalmic enophthalmos post-radiotherapy using a superiorlybased pedicled facial artery myomucosal (FAMM) flap as a new indication of this versatile flap after deepening of the skeletal framework with multiple calvarial and rib bone graft operations. 


\section{CASE}

We present the case of a 28-year-old man who underwent right eye enucleation for retinoblastoma when he was 3 years old and subsequently underwent chemotherapy and radiotherapy. $\mathrm{He}$ developed right eye socket contracture and right orbito-zygomatic and maxillary bone atrophy, and eye prosthesis insertion was impossible due to a shallow and contracted orbit. He underwent multiple surgical procedures at different hospitals to correct his shallow fornix, including right lower eyelid reconstruction at the age of 5 years with a skin graft and mucosal grafting. At the age of 8 years, he had a tissue expander inserted, with socket deepening and prosthesis insertion after orbital augmentation with rib cartilage. Nonetheless, the eye prosthesis failed to remain in place. He was then referred to our center at 26 years of age, after a long treatment gap with severe contracture of the socket. We reconstructed the depressed and atrophied right supraorbital ridge and right infraorbital region with a calvarial bone graft. A year later, the right inferior orbital rim was further augmented with a rib graft. The right eye socket was deepened and lined with a full-thickness skin graft 1 year later, and a conformer was inserted. Even with multiple operations, he kept having issues with the prosthesis, which continued to fall out. Finally, the upper eyelid contracture was corrected with a temporal forehead (Fricke) flap, expanding the inner upper eyelid lining, and a superiorly-based FAMM flap was used to treat the lower eyelid entropion and contracture. To the best of our knowledge based on the English-language literature, this is the first time that a FAMM flap has been used for lower lid or peri-orbital reconstruction. The facial artery course was located using handheld Doppler intraorally and the flap was designed over its pathway, as described by Pribaz et al. [8]. The flap out- line was marked on the right buccal mucosa, cantered over the facial artery in an oblique position from the retromolar trigon to the level of the ipsilateral gingival buccal sulcus. The anterior border was marked $1 \mathrm{~cm}$ posterior to the oral commissure till just before the orifice of Stensen's duct. The incision was made through the mucosa and buccinator muscle to identify the facial artery, which runs deep to the muscle when approached intraorally. The proximal (caudal) end of the facial artery was ligated and cut, and further dissection was done deep to the vessels to include it in the flap, which included part of the overlying buccinator muscle (Fig. 1A). The lower eyelid contracture was released, and then a tunnel was made from the intraoral location to the right lower eyelid. The FAMM flap was then brought to the defect (Fig. 1B). Once in place, the flap was inset to the lower eyelid. A transpositional local flap was made to assist closure over the medial canthus region (Fig. 1C) and the newly reconstructed orbit had sufficient volume to house a large conformer easily (Fig. 1D). Relatively good cosmesis was achieved postoperatively. A new prosthesis was made using a maxillofacial prosthetic unit according to the new space created for this patient, and good fit was maintained (Fig. 2). The patient provided full informed written consent for his clinical photographs to be published and the article was given a special exemption by the ethical committee (USM/JEPeM/19090546) to be published in this journal.

\section{DISCUSSION}

The radiation therapy that was given to our patient at a young age led to hypoplasia of the bone [9], which caused the facial asymmetry [10]. In addition, it caused contracture of the right eye socket due to post-radiation fibrosis. We addressed the skel-

\section{Fig. 1. Surgery using a facial artery myomucosal flap}

(A) Facial artery myomucosal flap was harvested from the right buccal mucosa. (B) The flap was tunneled through the right malar region into the eye socket. (C) After flap inset, a transpositional flap was made to assist closure. (D) Immediate postoperative view with the eye conformer in situ.
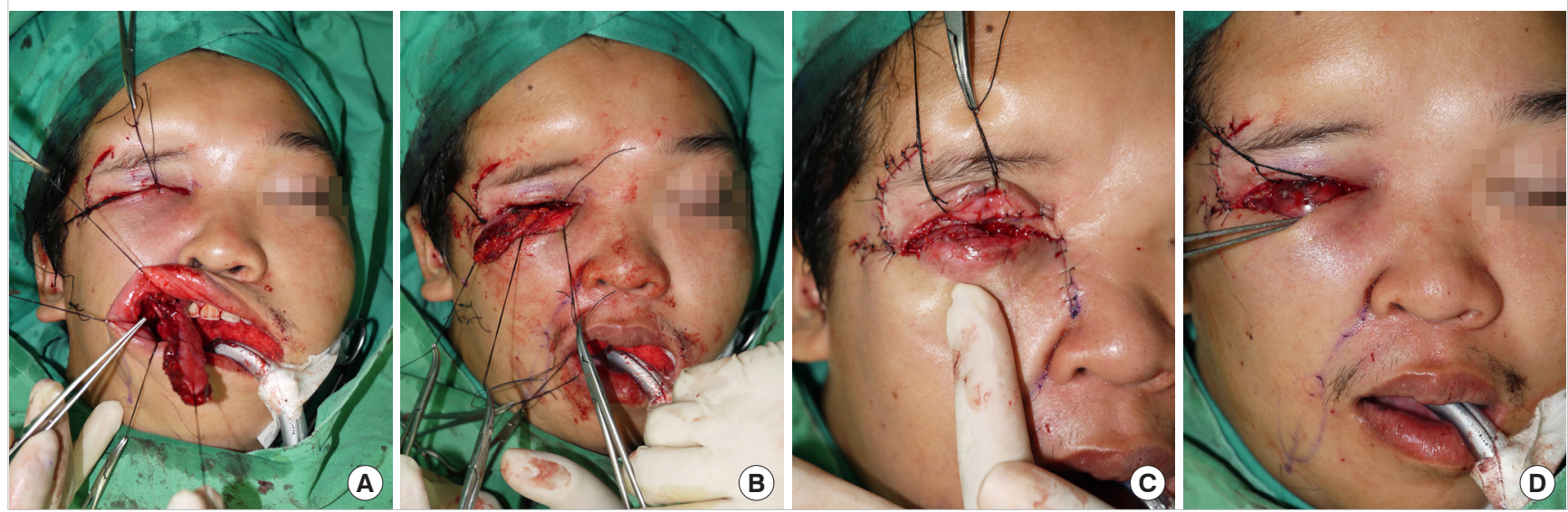


\section{Fig. 2. Preoperative and postoperative images}

$(A, B)$ Preoperative frontal and side views. (C, D) Seven-month postoperative frontal and side views.
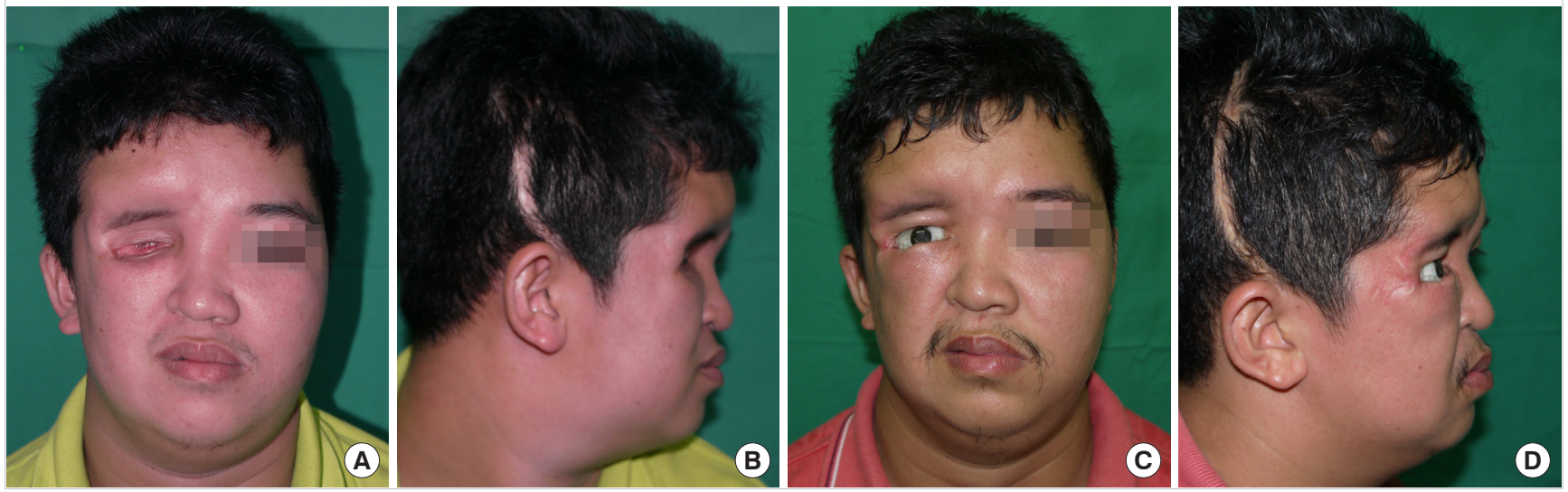

etal issue with calvarial bone grafting and rib grafting to correct the hypoplastic right orbit. However, he still had limited soft tissue, which failed to expand due to severe fibrosis. To solve this problem, we used a FAMM flap to create the inferior fornix soft tissue lining and base support for the prosthesis, complimented by a nasolabial transposition flap and Fricke flap for the upper eyelid. The FAMM flap is an axial flap that consists of mucosa and submucosa from the intraoral buccal region, part of the buccinator muscle, and the facial artery [8]. It is a robust flap with good blood flow and can be either superiorly-based (retrograde) or inferiorly-based (antegrade). It has a wide range of motion due to the duality of its pedicle, making it the flap of choice for intraoral reconstruction of small to medium defects $[8,11,12]$. It is versatile enough that it has been used for reconstruction of a neopharynx [13] and the base of the skull [14]. The facial artery course is easily traced and the axial blood supply makes it possible to create a long flap (5:1 length/width ratio), which then can be folded to suit the reconstructive needs [8]. The length of the flap allows the donor site to be closed primarily, reducing donor site morbidity. The bulk of this flap, when used to recreate the lower lid, results in a natural three-dimensional convex shape of the eye and expands the eye socket. To prevent compression of the pedicle, the medial canthus was released, and closure was done with a simple transpositional flap medially. Trismus is one of the known complications of this flap, which occurred transiently in our case. Its postoperative development can be avoided or treated by gradual mouth-opening exercises.

We report a new usage of the FAMM flap as another reconstructive choice for treatment of socket contracture, which resulted in favorable outcomes 7 months postoperatively with a relatively uncomplicated procedure. However, longer follow-up is needed to review the long-term results.

\section{NOTES}

\section{Conflict of interest}

No potential conflict of interest relevant to this article was reported.

\section{Ethical approval}

The study was approved a special exemption by the ethical committee (Exemption No. USM/JEPeM/19090546) and performed in accordance with the principles of the Declaration of Helsinki. Written informed consent was obtained.

\section{Patient consent}

The patient provided written informed consent for the publication and the use of his images.

\section{Author contribution}

Conceptualization: AZ Mat Saad, WA Wan Sulaiman, N Jamayet, A Hussein. Data curation: NR Nordin. Formal analysis: NR Nordin, N Jamayet, A Hussein. Funding acquisition: None. Methodology: AZ Mat Saad, NR Nordin, N Jamayet. Project administration: WA Wan Sulaiman, N Jamayet, SF Mat Johar, A Hussein. Visualization: AZ Mat Saad, N Jamayet, A Hussein. Writing - original draft: AZ Mat Saad, NR Nordin. Writing - review \& editing: all authors.

\section{ORCID}

Arman Zaharil Mat Saad

https://orcid.org/0000-0002-4003-6783

Nur Raihana Nordin https://orcid.org/0000-0002-6233-7704 Wan Azman Wan Sulaiman 
Siti Fatimah Noor Mat Johar

https://orcid.org/0000-0003-4120-4918

Adil Hussein

https://orcid.org/0000-0002-4224-5781

\section{REFERENCES}

1. Soll DB. The anophthalmic socket. Ophthalmology 1982; 89:407-23.

2. Camezind P, Robert PY, Adenis JP. Post-enucleation or evisceration socket syndrome. Oper Tech Oculoplastic Orbital Reconstr Surg 2001;4:48-51.

3. Payne WG, Naidu DK, Wheeler CK, et al. Wound healing in patients with cancer. Eplasty 2008;8:e9.

4. Shah CT, Hughes MO, Kirzhner M. Anophthalmic syndrome: a review of management. Ophthalmic Plast Reconstr Surg 2014;30:361-5.

5. Guberina C, Hornblass A, Meltzer MA, et al. Autogenous dermis-fat orbital implantation. Arch Ophthalmol 1983; 101:1586-90.

6. Smith RJ, Malet T. Auricular cartilage grafting to correct lower conjunctival fornix retraction and eyelid malposition in anophthalmic patients. Ophthalmic Plast Reconstr Surg 2008;24:13-8.

7. Yanaga H, Mori S. Eyelids and eye socket reconstruction us- ing the expanded forehead flap and scapha composite grafting. Plast Reconstr Surg 2001;108:8-16.

8. Pribaz J, Stephens W, Crespo L, et al. A new intraoral flap: facial artery musculomucosal (FAMM) flap. Plast Reconstr Surg 1992;90:421-9.

9. Goldwein JW. Effects of radiation therapy on skeletal growth in childhood. Clin Orthop Relat Res 1991;(262):101-7.

10. Denys D, Kaste SC, Kun LE, et al. The effects of radiation on craniofacial skeletal growth: a quantitative study. Int $\mathrm{J} \mathrm{Pe}-$ diatr Otorhinolaryngol 1998;45:7-13.

11. Ariffuddin I, Arman Zaharil MS, Wan Azman WS, et al. The use of facial artery musculomucosal (FAMM) readvancement flap in closure of recurrent oronasal fistula. Med J Malaysia 2018;73:112-3.

12. Ayad T, Kolb F, De Mones E, et al. Reconstruction of floor of mouth defects by the facial artery musculo-mucosal flap following cancer ablation. Head Neck 2008;30:437-45.

13. Frisch T. Versatility of the facial artery myomucosal island flap in neopharyngeal reconstruction. Head Neck 2017;39: E29-33.

14. Xie L, Lavigne P, Lavigne F, et al. Modified facial artery musculomucosal flap for reconstruction of posterior skull base defects. J Neurol Surg Rep 2016;77:e98-101. 